\title{
LOS TERREMOTOS DE ANDALUCÍA (1884-1885) Y EL COMPROMISO SOCIAL DE LA PRENSA. EL DÍA Y SU NÚMERO EXTRAORDINARIO (27-I-1885)
}

\section{The Earthquakes in Andalucía (1884-1885) and the Social Commitment of the Press. El Dia and its Extraordinary Number (27-I-1885)}

\author{
PILAR GARCÍA PINACHO \\ Universidad CEU San Pablo \\ pinacho.fhm@ceu.es \\ ORCID ID: 0000-0002-9509-8375
}

Recibido: 05-10-2021 / Aceptado: 09-11-2021 DOI: https://doi.org/10.51743/cilh.vi47.250

RESUMEN

Tras los terremotos de Andalucía de diciembre de 1884 la prensa fue ejemplo de solidaridad con los damnificados. El Día publicó un número extraordinario con las hasta ahora desconocidas contribuciones de Emilia Pardo Bazán, Pedro Antonio de Alarcón, Ramón de Campoamor, José Zorrilla, Gaspar Núñez de Arce, José Echegaray, Emilio Castelar y Ripoll, Segismundo Moret y Prendergast, Joaquín Costa Martínez y Carrie Houghton.

PALABRAS ClAVE: prensa siglo XIX; El Día; Periodismo y Literatura; terremotos Andalucía.

ABSTRACT

After the earthquakes in Andalusia in December 1884 the press was an example of solidarity with the victims. El Día published a special number with the until now unknown contributions of Emilia Pardo Bazán, Pedro Antonio de Alarcón, Ramón de Campoamor, José Zorrilla, Gaspar Núñez de Arce, José Echegaray, Emilio Castelar y Ripoll, Segismundo Moret y Prendergast, Joaquín Costa Martínez and Carrie Houghton.

KEY WORDS: 19th -century press; El Día; Journalism and Literature; Earthquakes Andalusia. 


\title{
LOS TERREMOTOS DE ANDALUCÍA (1884-1885) Y EL COMPROMISO SOCIAL DE LA PRENSA. EL DÍA Y SU NÚMERO EXTRAORDINARIO (27-I-1885)
}

\author{
Pilar GARCía PinACHO \\ Universidad San Pablo- CEU
}

«A LAS NUEVE de la noche del día de Navidad del año 1884 sintiose en España un terremoto. En los siguientes días sucediéronse, unas después de otras, las más desgarradoras noticias». Así comenzaba el relato del Comisario Regio para la reedificación de los pueblos destruidos por los terremotos en las provincias de Granada y Málaga, Manuel Lasala y Collado [1888: 13], nombrado por Real decreto de 13 de abril de 1885 [Lasala, 1888: 8]. Después, hace un somero recuento de los daños: «más de cien poblaciones habían padecido espantosamente» $\mathrm{y}$ «2.000 personas habían quedado muertas o heridas en las provincias de Granada v Málaga» [Lasala, 1888: 13]. Más exactamente, perdieron la vida entre 750 y 900 personas y fue necesaria la reedificación de más de mil viviendas y la reparación de unas catorce mil [López, Martín y Mezcua 1981: 5].

Inmediatamente después, en el mismo párrafo, ya destacaba que «la caridad universal», que había sido estimulada por «el Gobierno y la Prensa», fue «una de esas expansiones generosas que son el honor eterno de la humanidad» [Lasala, 1888: 13]. 
En particular, recalcaba que el capital conseguido por la suscrición nacional ascendía a casi seis millones y medio de pesetas, «en gran parte a causa del generosísimo concurso de la caridad extranjera», que, puntualizaba Lasala, «ha llegado a aportar una suma casi igual a la que reunió la caridad española» [1888: 17].

Sin embargo, es de especial importancia que, dado que el coste material de la reconstrucción ascendió a diez millones de pesetas, hace notar que fueron determinantes e imprescindibles las aportaciones de distintas instituciones y personas que cubrieron la diferencia entre lo conseguido en la citada suscrición y la cantidad necesaria. Entre ellas, el político y escritor guipuzcoano menciona explícitamente las recaudaciones obtenidas por dos periódicos, La Correspondencia de España y El Imparcial, por la prensa «terceirense» y por el duque de Fernán-Núñez [1888: 17-18].

Al día siguiente de los terremotos, sin embargo, y a pesar de la magnitud del fenómeno, los periódicos españoles de difusión nacional de mayor tirada, todos madrileños, pusieron el foco en los temblores que se produjeron en Madrid aquella misma noche, aunque no se dejaba de apuntar únicamente que el terremoto se había «sentido con mayor intensidad» [El Imparcial, 26-XII, 1884: h. 1v. c. 3] y a «la misma hora» [La Correspondencia de España, 26-XII, 1884: h. 1v c.4] en las provincias de Granada, Málaga, Jaén y Córdoba.

Mientras tanto, El Globo [26-XII, 1884: h. 1v. c. 1] parece que fue el único que trató con preocupación lo que había sucedido en Andalucía, y con una gran profesionalidad, digna de encomio, informaba de «que por ahí se dijo que había despachos oficiales anunciando la repetición del fenómeno terrestre en Lisboa, Granada, Málaga y Córdoba» y aseguraba que había habido «desgracias en la segunda y tercera de dichas capitales». Todo ello le hizo acudir a la fuente de las noticias, al Ministerio de la Gobernación, donde pudieron confirmarlo y añadir el detalle de la muerte de una anciana y una niña en Málaga.

El día 27 todos los diarios comenzaron a relatar, sin atisbar todavía 
la verdadera proporción del suceso, más noticias, otra vez, con especial atención a lo ocurrido en Madrid, pero ya publicaban relatos acerca de edificios derrumbados en Andalucía, donde sus habitantes habían quedado atrapados.

Especialmente gráfico resultaba el relato, publicado en La Correspondencia de España [26-XII, 1884: h. 2r. c. 4], del encargado de la estación telegráfica de Vélez-Málaga, en la sección de «Edición de la noche de ayer 26 de diciembre». Herido en un brazo, su lugar de trabajo había sido desalojado y, ya nuevamente acomodado «bajo un tinglado», procedía a calificar de «horrible» el terremoto, que había causado «muchas víctimas y heridos, habiendo arruinado muchas casas, quedando las demás amenazando ruina». Para completar el cuadro, narraba que después había habido un fuerte temporal y que la gente se agolpaba a la puerta de su improvisada oficina para mandar telegramas a su familia. Heroicamente, terminaba declarando: «Estoy sin descansar y sin comer, tal es el pánico que tenemos. Sin embargo, estoy dispuesto a resistir hasta el último trance».

A partir del día 29, casi todos los diarios comienzan una sección dedicada exclusivamente a lo referido en Andalucía, que pasa a ser el centro de atención del acontecimiento; ya se pormenorizan, por fin, datos de víctimas, heridos y damnificados, daños y algún relato particular y salta, por fin, además, a la primera página, aunque solo en algún caso: en El Imparcial, «Los temblores de tierra» [26-XII, 1884: h. 1r. c. 3]; en El Liberal, «El terremoto de anoche» [26-XII, 1884: h. 2r, c. 2]; o, en El Globo, «Los temblores de tierra en Andalucía» [30-XII, 1884: h. 2r. c. 1].

\section{LA GENEROSIDAD DE INSTITUCIONES Y PERSONAS PARA AUXILIO DE ANDALUCÍA}

Desde los primeros días se hizo plausible que el fondo de Calamidades Públicas sería insuficiente para atender las necesidades de los damnificados, por lo que la sociedad civil española tuvo que reaccio- 
nar inmediatamente ante esta evidencia, no sin críticas. Así, El Liberal, fiel a su rol de oposición, denuncia que el Fondo de Calamidades no bastaba y, bajo el título de «iCaridad!» [31-XII, 1884: h. 1r. c. 1], en su artículo editorial, cuestionaba si el señor Cánovas se habría enterado de la gravedad de la situación. El Imparcial [3-I, 1885: h. 1r. c. 1-2] añadía, en «La caridad española», que ya era algo tarde, pero que, aun así, había que volcarse con los afectados.

Poco a poco, aparecen noticias de acciones solidarias, como la del conde de Aliatar que organizaba a tal efecto destinar la recaudación de todos los teatros de Madrid [La Iberia, 3-I, 1885: h. 2r. c. 2-3; y El Liberal, 3-I, 1885: h. 2v, c. 2.], lo que se va anunciado en los días siguientes en las carteleras publicadas en los periódicos.

La prensa española se movilizó también, como era habitual, para conseguir fondos. La primera noticia [La Época, 3-I, 1885: h. 2r. c. 3] es una reunión en la de capital organizada por el marqués de Santa Ana, propietario de La Correspondencia de España, para que esta, «unida en uno solo, humanitario y patriótico sentimiento», se responsabilizara de que la ayuda llegara a las provincias afectadas, para lo que contaba ya con los periódicos de provincias, y la empresa de ferrocarriles andaluces y del Mediterráneo. Por unanimidad se nombró una comisión ejecutiva, se cuenta con el ofrecimiento del Teatro Real para hacer una función especial y del Hotel de Ventas para organizar una exposición. El Día [3-I, 1885: h. 1v. c. 2], sin embargo, decía que en esta reunión no se llegó a ningún acuerdo particular.

Esa misma tarde, los directores de los periódicos madrileños se dieron cita en Gobernación con el fin de concretar ayudas, junto con los de casinos, sociedades y círculos varios [La República, 6-I, 1885: h. 1r. c. 4 - 1v. c. 1-2], como lo hicieron de igual manera todos los de Barcelona [La Dinastía, 4-I, 1885: 64-65] y muchos periódicos de provincias, que abrieron directamente suscriciones y enumeraban los donativos de cada persona o institución que colaboraba con cual- 
quier cantidad ${ }^{1}$. De hecho, la prensa está llena de referencias a estos actos, como muestra el artículo de El Liberal, de Madrid, en «Donativos, suscriciones y ofrecimientos» [25-I, 1885: h. 2r. c. 1].

Pero, aunque no se llegara a acuerdo alguno, los periódicos de mayor tirada, como subrayaba el Comisario Regio para la Reconstrucción, algunos rotativos emprendieron con éxito distintas acciones con el fin de recaudar fondos, caso de La Correspondencia de España y El Imparcial, como lo hizo igualmente El Liberal.

Por su parte, el nuevo periódico El Día acometió la tarea de hacer un número extraordinario de su diario con textos de los mejores escritores, periodistas y políticos y dibujos de los más afamados ilustradores del momento. La particularidad de este número es que se vendería por primera vez en la gran fiesta que ofrecieron en el palacio de Cervellón los duques de FernánNúñez en la noche del martes 27 de enero de $1885^{2}$. Un periódico satírico madrileño, La Broma, «órgana política liberala», también publicó con el mismo objeto otro número extraordinario [García Pinacho y Menéndez Onrubia, 2021: 75].

La expectación que generó la fiesta fue alimentada por otros papeles y por el periódico que había fundado casi cinco años antes el marqués de Riscal. Desde el día 23 de enero de 1885, onomástica de Alfonso XII, que acababa de volver de visitar la zona más afectada, ya se empieza a hablar de la recepción y del número extraordinario de El Día y, en los días siguientes, se van dando detalles: como una rifa, baile, concierto y personalidades que asistirían...

${ }^{1}$ Véase, por ejemplo, Crónica Meridional (Almería) [13-I, 1885: h. 1r.-h. 2r.] que publica los donativos nominales - «Sociedad de Socorros mutuos la Bienhechora»-, enumera ya unas cuantas iniciativas concretas -«En el Círculo de la Unión Mercantil»; y «Donativos, suscriciones y ofrecimientos»- y llena su «Gacetilla» con diversos actos que se van anunciando o llevando a cabo.

${ }^{2}$ Véanse para todos los detalles y pormenores de la fiesta y la venta del número extraordinario el trabajo de García Pinacho y Menéndez Onrubia, «La Hija Mimada (1885): Un desconocido relato breve de Pérez Galdós», 2021: 67-88. 
[La Correspondencia de España, 23-I, 1885: h. 2r. c. 1; La Correspondencia de España, 26-I, 1885: h. 1r. c. 4; El Liberal, 27-I, 1885: h. 2r. c. 2-3; La Paz (Murcia), 27-I, 1885: h. 1v.], sobre todo, la familia real [La Correspondencia de España, 28-I, 1885: h. 1v. c. 1; El Bien Público (Mahón), 29-I, 1885: h. 1v.].

La fiesta fue célebre, o, por lo menos, así se refleja en la prensa española, donde se han encontrado trece crónicas que detallan distintos aspectos del evento3: «La vida madrileña», El Imparcial, [28-I, 1885: h. 2r, c. 2-4]; «Telegramas. Servicio especial de El Bien Público», en El Bien Público de Mahón [28-I, 1885: h. 2r.], que apunta que se recaudaron sesenta mil pesetas; «El concierto y la rifa de los duques de Fernán-Núñez», El Día [28-I, 1885: h. 1r. c. 2-4]; «Edición de la noche de hoy 28 de enero», en La Correspondencia de España [29-I, 1885: h. 2r. c. 3]; "Terremotos y socorros», en La Paz de Murcia [29-I, 1885: h. 1v. c. 2-3]; «La Vida madrileña», en El Constitucional Dinástico de Alicante [30-I, 1885: h. 1r. c. 3-5; 1v. c.1 ]; «En casa de Fernán-Núñez», firmado por «Almaviva», en El Guadalete de Jerez de la Frontera [30-I, 1885: h. 1r c. 5-1v c. 1.]; «Alcance» ${ }^{4}$, en El Serpis de Alcoy [30-I, 1885: h. 2r. c. 2]; "Correspondencia de El Demócrata. Cartas de Madrid», en el periódico gerundense El Demócrata [1-II, 1885: h. 1v. c. 3-4], firmada por A. L.; en Gandía, «Revista General», en El Litoral [1-II, 1885: h. 1v. c. 1]; el también gerundense La Lucha, publica «Madrid 29 de enero de 1885» [1-II, 1885: h. 1v. c. 3-4], firmada por «El Corresponsal»; El Balear, de Palma de Mallorca lo titula «Concierto-rifa de los señores duques de Fernán-Núñez» [4-

${ }^{3}$ Las informaciones de casi todos los diarios de provincias, incluidas las firmadas por Alfredo Escobar y Ramírez, «Almaviva», proceden de la Agencia Española, identificados como clientes seguros El Serpis, La Paz de Murcia, Crónica Meridional y La Lucha [Axeito, 2017: 19, 108-109], aunque todas las crónicas extensas halladas contienen la misma información, por lo que es probable que los demás estuvieran suscritos a la misma agencia.

${ }_{4}^{4}$ «Alcance» es una sección de revista de prensa y resume lo que dicen otros periódicos. 
II, 1885: h. 1r. c. 1-4-1v. c. 1]; «Los duques de Fernán-Núñez. Madrid, 28», también en El Bien Público de Mahón [4-II, 1885: h. 1r. c. 4-5 a -1v. c. 1-2], por Almaviva. Además, El Correo de Cantabria, publicó un breve acerca de la fiesta [30-I, 1885: h. 2r. c. 2] y La Paz de Murcia [30-I, 1885: h. 1v. c.1], en otro breve, anuncia que el dinero de la fiesta se destinaría a la construcción de casas.

A pesar de ello, no faltaron las críticas, por ejemplo, cuando se acusó de despilfarrar en este tipo de eventos, ya que el gasto de la fiesta había sido supuestamente superior a los ingresos [El Balear, 4-II, 1885: 2].

La asistencia, amén de la familia real y del presidente del Consejo, se adornaba con varios ministros -Gobernación, Ultramar y Gracia y Justicia-, representantes de países extranjeros, lo más florido de la nobleza española, el canto y «los baqueros más opulentos» [El Serpis, 30-I, 1885: h. 2r. c.2].

\section{El Día. Diario Político}

El Día era un moderno y joven periódico madrileño impulsado por Camilo Hurtado de Amézaga y Balmaseda, marqués de Riscal, teniendo como objetivo conseguir que fuera un medio que llegara a ser el equivalente de The Times en España, y como indican Saillard [2005] y Lissorgues [2009] no era el primer intento de hacerlo. De hecho, en 1858, había fundado otro diario con el mismo nombre financiado por sus padres, pero sin éxito. Con nuevos fondos, por fin, su nueva empresa periodística vio la luz el significativo día 23 de abril del año 1880. Y, aunque este dato no consta en la bibliografía más general, así lo anuncian tres medios madrileños. El Diario de Avisos de Madrid [23-I-1880: h. 1v.], que solía hacerse eco de las novedades de este tipo, que dice haber recibido «el primer número del nuevo periódico el Día» y que le da la bienvenida y de desea «mucha 
luz». El Demócrata [23-I-1880: h. 1v. c. 1], en «Opiniones y comentarios», siguiendo la misma línea, anuncia que «Otro diario nuevo ha visitado nuestra redacción el nuevo periódico El Día, publicación llena de interesantes noticias, y a la cual deseamos prosperidad y larga vida». Otro diario que lo reseña es El Fígaro [23-I-1880: h. 1v. c. 1], que comenta que «Esta mañana nos ha visitado por primera vez el nuevo periódico, titulado: El Día» y, como hiciera el anterior, saluda «afectuosamente a nuestro colega, deseándole larga vida, mucha suscrición y paz». Este último, sin embargo, es el único de los tres que publica la declaración de intenciones del recién nacido: «He aquí la síntesis de su programa político: "Sinceridad en las elecciones a Cortes. -Justicia pronta, eficaz, independiente. -Leyes administrativas, duraderas y simplificadas: empleados estables y responsables. Orden y economía en la Hacienda”». Por su parte, El Liberal [23-I1880: h. 1r. c. 4], periódico de oposición al gobierno de Antonio Cánovas del Castillo, lo acusa de ser liberal conservador, es decir, ministerial, al relacionar al nuevo diario con La Política.

Así que, en esta segunda ocasión, la iniciativa sí cuajó, como prueba la continuidad y constancia de la periodicidad diaria, mostrada desde el primer número conservado en los fondos digitalizados de la Hemeroteca Nacional [1 de febrero de 1882], donde se data como número 589 en su cabecera.

En este primer número de la colección, en la cuarta página y en todo su ancho, bajo la publicidad, «El Día. Diario político», aclara varias cuestiones creyéndose «en el caso de manifestar al público los medios con que cuenta para realizar su programa», dándolo por conocido «las personas que [lo] leen». En el mismo párrafo explica su «organización interior» con las mejoras acometidas que lo convierten en «uno de los primeros que se publican en Europa».

Lo primero que destacaba, entonces, es que el diario tenía tres ediciones: «una para el correo del Norte, otra para el del Mediodía y otra para Madrid» y que «un numeroso personal de redactores y no- 
ticieros» le permitían «tratar todas las cuestiones políticas, financieras, administrativas y los sucesos que interesan al país» para "enterar a sus lectores de los acontecimientos que diariamente ocurren».

También llama la atención sobre sus corresponsalías en Nueva York y París y la suscripción a un servicio telegráfico para la información extranjera, así como «corresponsales en todas las capitales de provincia de España y en los pueblos de importancia, con autorización para poner telegramas siempre que haya sucesos de interés».

Además, informa de que «Desde principios de año. El Día tendrá montada una imprenta para su servicio exclusivo, reuniendo en un mismo local imprenta, redacción y administración», por entonces, como se lee en su pie de imprenta, en la calle de la Almudena, número 2, y promete hacer «nuevos sacrificios para demostrar que lo mismo en la prensa que en otros ramos de la cultura, España entra de lleno por el camino del progreso».

La mejor prueba de su éxito es la evolución ascendente de lo que el periódico paga a Hacienda por derechos de Timbre y su escalada hacia los primeros puestos de las tablas, más aún habida cuenta que los tres diarios que aparecen siempre a la cabeza de los pagos, y, por tanto, parece que de las tiradas -La Correspondencia de España, El Liberal y El Imparcial- pagan más porque tienen más peso $^{5}$. La primera vez que El Día aparece en la «Nota de la recaudación obtenida por el derecho del timbre de periódicos para la Península, Antillas y Filipinas» fue en la nota publicada en la $\mathrm{Ga}$ ceta de Madrid del 17 de agosto de 1880 [515] y ya por encima de papeles tan conocidos como La Discusión y El Pabellón Nacional. Dos años después, en enero de 1882, solo pagan más que El Día, los tres citados anteriormente y El Globo, El Siglo Futuro y La Iberia [Gaceta de Madrid, 15-I-1882: 224]. Al año siguiente ya aparece

5 Véase, por ejemplo, «Nota de la recaudación obtenida por el derecho de timbre de periódicos para la Península, Antillas y Filipinas», en Gaceta de Madrid, 16-IX1880: 889 . 
por encima de La Iberia, El Siglo Futuro y La Época [Gaceta de Madrid, 17-I-1883: 129].

Esta situación siempre se mantuvo, aunque hay que hacer notar que solo aparecía en los estadillos de timbre para la Península de periódicos políticos y nunca en los de las Antillas o Filipinas.

Entre sus redactores estuvieron, según Ossorio y Bernard [1903], Juan de Alvarado [31], Vital Aza y Bulla [50], Luis Barthe y Zelayeta [60], Alejando Benisa [64], Salvador Canals [87], José Gutiérrez Abascal [205], Federico Lafuente y López -Elías [233], Carlos Leonor [239], Carlos Malagarriga [262], Bernardino Martín Mínguez [270] o Ricardo Sepúlveda y Panter [441], Enrique Pastor y Bedoya [345], Servando Ruiz Gómez [414]. Ossorio y Bernard cita como corresponsal en Almería a Ramón Cruz Uclés [114], en Barcelona a Manuel Escudé y Bartolí [135], colaborador desde La Habana a Antonio Escobar y Laredo [135], Sánchez de Neira desde Londres [428] y Francisco Gutiérrez Brito desde París [206].

Tuvo además a Antonio Peña y Goñi [350] como crítico teatral, a José Gutiérrez Abascal, Kasabal, como cronista de sociedad [Nuevo Mundo, 4-I-1907: h. 6v.], a Luis Navarro y Calvo [313] como crítico musical, a Ramiro Leza y Agost para asuntos artísticos [240]. Entre los nombres más célebres de su nómina figuran Sinesio Delgado [123], Antonio Fernández Grilo [149], José de Letamendi y Manjarrés [240], Salvador Quevedo y Zubieta [376], José Millán Astray [293], José Ramón Mélida «colaborador muy activo» [285], Francisco Silvela y de Le Vieilleuze [445], Vicente Vera y López o Doctor Hispanus [485], Ramón Navarrete y Landa [312], Gaspar Núñez de Arce [318], Manuel Tolosa Latour [461] y Juan Valero de Tornos [447].

Entre sus directores estuvieron Luis López Ballesteros [244], Juan de Quesada, redactor de El Día desde su fundación y director entre 1884 y 1897 [376] -es decir, cuando se publicó el número extraordinario que nos ocupa-, Enrique Sepúlveda y Planter [441], Luis Soler 
y Casajuana, entre 1897 y 1898 [448], y Antonio Santonja [434]. El mismo Manuel Ossorio y Bernard se cita a él mismo y a su hijo, Carlos Ossorio y Gallardo, como colaboradores [331] y le dedica palabras muy sentidas y llenas de admiración al fundador, Camilo Hurtado de Amézaga [217]. Aparte, en el suplemento literario, tuvo en nómina a Leopoldo Alas Clarín [Pascual, 2001], Antonio Alcalá Galiano, Emilio Castelar y Armando Palacio Valdés.

Tras la muerte de su fundador, en 1886, fue comprado por Segismundo Moret y Prendergast y, en 1898, Antonio Santonja consiguió la propiedad y lo dirigió.

\section{EL NÚMERO EXTRAORDINARIO DE EL DÍA DE 27 DE FEBRERO DE 1885}

El número extraordinario de El Día de 27 de febrero de 1885 cuya venta fue destinada «al alivio de los pueblos de las provincias de Granada y Málaga perjudicados por los recientes terremotos» no fue el primer número extraordinario que publicó este diario. El primero había sido el que salió a la luz el día 25 de mayo de 1881, dedicado a Pedro Calderón de la Barca en el segundo centenario de su muerte. En él colaboraron, por orden de aparición, Antonio Cánovas del Castillo, conde de Casa Valencia, Cayetano Vidal de Valenciano, J. Talero, Pedro Antonio de Alarcón, Emilio Castelar, Manuel Cañete, Pedro de Madrazo, Manuel Menéndez y Pelayo, José Monmeneu y Vicente de Vera y López.

Este precioso número imita una gaceta del siglo XVII, no en formato, pero sí en el tipo de lenguaje, los géneros periodísticos y relatos de la época, y lo componen cartas, avisos, supuestas noticias, etc. El formato era tan espectacular que fue objeto de una reseña minuciosa en la revista francesa Le Livre: revue mensuelle [Pompeyo Gener, 1881: 
394] en un artículo dedicado a la conmemoración en España de tan ilustre centenario.

A pesar de que el número publicado para ayudar a los afectados por los terremotos no resultaba tan llamativo en la tipografía como el dedicado a Calderón de la Barca, sí contó con las mejores firmas del momento: repetían colaboración Antonio Cánovas del Castillo, el conde de Casa Valencia y Pedro Antonio de Alarcón, a los que se sumaban redactores y colaboradores habituales del diario, como $\mathrm{Ka}$ sabal, y Gaspar Núñez de Arce. Sin embargo, además, en esta ocasión. aparecen las firmas de Emilia Pardo Bazán, Carrie Houghton, Segismundo Moret, Gabriel Rodríguez, Benito Pérez Galdós, Joaquín Costa, Doctor Hispanus, José Zorrilla, José de Echegaray, Gaspar Núñez de Arce, Leopoldo Cano, Ramón de Campoamor, Manuel Ortiz de Pinedo y los dibujos de Arturo Mélida, A. Gomar, A. de Beruete y Horacio Lengo.

Todo ello hace que no fuera de extrañar que, en la memorable fiesta de los Fernán-Núñez, tras la llegada de los reyes, lo primero que se organizara fuera la venta de los ejemplares de El Día, e incluso hubo una productiva reventa. La promoción que de este número hizo el mismo rotativo, además de reseñas en otras publicaciones, fue tan llamativa como la fiesta: anuncios en las cuartas páginas y llamadas de atención en las primeras columnas de las primeras páginas, desde el día 25 de enero -19 en total, hasta el día dos de marzo-; en los anuncios de las cuartas se insertaba un sumario completo, con añadidos esporádicos y algún cambio nimio de títulos de los textos; se daban indicaciones de precios especiales a quienes compraran cincuenta ejemplares y se daba una dirección en París donde se podía adquirir; el mismo día 28 publicó una extensa crónica del evento escrita por una «amiga de El Día» [28-II, 1885: h. 1r. c. 4], ante la enfermedad del cronista habitual, José Gutirrez Abascal [García Pinacho y Menéndez Onrubia, 2021: 71-74].

Finalmente, la venta en el baile fue de 650 ejemplares, de una tira- 
da total de seis mil, vendido el resto en otras provincias españolas y en la propia administración del periódico ${ }^{6}$ [García Pinacho y Menéndez Onrubia, 2021: 74].

El número se abre con el programa del concierto que se ofrecía en la casa de los Fernán-Núñez partido por el dibujo de Arturo Mélida (Imagen 1) en forma de cruz que llega hasta el final de la página, y cuyo crucero ocupa las dos columnas centrales de las cuatro que la componen. El dibujo representa, como había anunciado en tantas ocasiones el diario, lo que describe perfectamente su título: La Caridad, Escudos de Granada y Málaga, Las armas de la casa de Cervellón, y está fechado en enero de 1883 [h. 1, r.]. Otro de los tres dibujos que ilustran el ejemplar es Un recuerdo de Granada (Imagen 2) del pintor valenciano Antonio Gomar [h. 2, r. c. 2-3]. Una playa (Imagen 3) es obra del pintor paisajista Aureliano de Beruete [h. 2, r. c. 1-4]. iViva la Caridad! (Imagen 4) es un dibujo del malagueño Horacio Lengo [h. 2 v. c. 2-3], ilustrador de La Ilustración Católica y de la Ilustración Española y Americana. Los cuatro artistas pertenecían a un amplio círculo de pintores, escritores y políticos españoles finiseculares.

A los lados, y saltando a la segunda página, a lo largo de más de una columna, se halla un artículo, que podríamos calificar de reportaje especial, desde el punto de vista de su género periodístico, ya que combina información acerca del palacio y su historia, enriquece el texto con amplias descripciones y numerosos elementos ambientales. En el texto, de Kasabal, firmado como F. G. Abascal, y de título «El palacio de Cervellón y sus fiestas», el que el periodista abre con un panegírico a los duques y a su familia y sigue con la ubicación de la edificación, en lo que fue un antiguo arrabal en el tiempo de Felipe II y en la que construyó su morada el primer conde de Cervellón, después muy transformada, que resulta un edificio de «aspecto mo-

\footnotetext{
${ }^{6}$ Para entonces, las oficinas del periódico habían pasado a estar en la carrera de San Jerónimo 45 y 47, como se aprecia en la parte superior derecha del número.
} 
nótono de casa moderna». Esto, señala, no tiene nada que ver con el opulento interior descrito con minuciosidad. A continuación, reseña alguna de las fiestas más notables habidas en el palacio y augura que cuando los invitados salgan "podrán tener la satisfacción de haber contribuido a enjugar algunas lágrimas» [h. 1, r. c. 1-4 - v. c. 1-2].

Muy adecuado también a su género periodístico, es el artículo sin firma que cierra el número, ya que es un artículo de fondo en que se alaba la caridad de todo tipo de personas para los damnificados de los terremotos y de agradecimiento a los personajes que han colaborado del mismo. Asimismo, exige la pronta rehabilitación o reconstrucción de las infraestructuras y viviendas a la mayor brevedad. La única diferencia con los artículos editoriales habituales en la época es la ubicación en el ejemplar, ya que estos suelen abrir los diarios, quedándoles reservados la primera o primeras columnas de apertura en la primera página.

\section{LAS FIRMAS MÁS ILUSTRES. ESCRITORES, ARTISTAS Y POLÍTICOS}

De entre los escritores más afamados, El Día consiguió las colaboraciones de Benito Pérez Galdós, Emilia Pardo Bazán, Pedro Antonio de Alarcón, Ramón de Campoamor, José Zorrilla, Gaspar Núñez de Arce y José Echegaray; y, aunque muchos de estos también destacaron en la literatura y en otras áreas, son más conocidos por su trayectoria política Emilio Castelar y Ripoll, Segismundo Moret y Prendergast y Joaquín Costa Martínez; entre los artistas, además de los ilustradores, sobresale un texto de Carrie Houghton.

Todos sus trabajos poseen características de géneros periodísticos marcadamente de opinión y todos giran, como es lógico, en torno a la actualidad del número extraordinario de El Día, que nos ocupa. Casi todos ellos, como veremos, cumplen también la función poética de la literatura, literariedad, según la entienden Simone Winko y Jacobson, ya que, como determina Janette Kranz [2020: 65] se trata 
de un género híbrido. Esta hibridación consiste en la producción de una «micro-obra literaria que $-\mathrm{y}$ en eso se distingue de cualquier obra literaria habitual-, depende e interactúa con su molde periodístico», es decir, "como parte íntegra de un género en el fondo periodístico» [Kranz, 2020: 14]. Todo ello no podía haber sido de otra manera, ya que la mayoría de ellos tuvieron una fecunda obra periodística, además de literaria o política, cuando no las tres juntas [García Pinacho, 2014]. Los once textos giran en torno a uno de los tres subtemas relacionados con la actualidad periodística que impone el medio: los terremotos, la caridad y la fe.

Los textos -que se reproducen en el apéndice porque son, que sepamos, desconocidos 7 - que más concuerdan con comentarios breves de opinión son los escritos en verso. De la temática «terremotos» son los de Zorrilla, que le dedica su estrofa a Granada [28-I: h. 1r. c. 2]; Núñez de Arce [27-I: h. 1v c. 4]; y Campoamor [27-I: h. 1v. c. 3]; y de la temática «caridad» es el de José Echegaray [27-I: h. 2r.c. 1]. Sin embargo, el texto que más concuerda con el comentario de opinión es «Conjetura» de Pardo Bazán [27-I: h. 1v. c. 4], que, por cierto, siempre fue anunciado por El Día en plural, «Conjeturas». En él, la gallega no puede creer que la tierra sea la culpable del fenómeno, sino que piensa que «obedece en sus convulsiones a una fuerza superior, oculta y fatal; de otro modo no desplomaría escombros sobre las cunas ni ahogaría bajo un techo a la madre con el niño en brazos». Tampoco es mucho más extenso el comentario que Moret dedica a la caridad [27-I: h. 1v. 4].

En cuanto al escrito de Moret [27-I: h. 1v. c. 3-4], dedicado a la caridad, sobrio y conciso, concluye que, cuando ya no hay esperanza, «brilla a lo lejos, y en medio de los horrores de la destrucción,

${ }^{7}$ No se adjuntan «La hija mimada» de Benito Pérez Galdós (García Pinacho y Menéndez Onrubia, 2021: 67-89), ni el de Pedro Antonio de Alarcón (1891), recopilado como «La fuerza física, la fuerza social y la fuerza moral», en Últimos escritos (Madrid, Imprenta y fundición de M. Tello), 143-150. 
[...]como ángel de redención para el desamparado y de consuelo para el afligido: la caridad».

Bastante más extensas son las colaboraciones de Castelar, Alarcón, Costa, Houghton y Pérez Galdós.

La participación de Benito Pérez Galdós es un cuento [27-I: h. 2r. c. 1-4], «La hija Mimada», en el que Dios, a pesar de todas las veleidades y locuras de su hija Caridad - YYa el escándalo es demasiado notorio»-, la prefiere sobre las demás -«Es la predilecta, la niña mimada del Cielo y de la Tierra»-. Las otras dos, Esperanza y Fe, eran «hermanas acusadoras». El padre sentenciaba al respecto: «Ya sabía yo que con el trato humano participaríais de humanas debilidades. No importa. Seguid: sed humanas, sin dejar de ser divinas, y tomad ejemplo de mí, que siendo quien soy, también fui hombre».

No es muy distinto el relato que se publica de Carrie Houghton, «El ochavo de la viuda» [27-I: h. 2r. c. 4-h. 2v. c. 1.], solo que, en este caso, con una parábola quiere mostrar que cualquier donativo, por pequeño que sea, podrá ayudar a paliar la desgracias: «estos pequeños óbolos sumarán millones para remediar muchos males y serán tan gratos a los ojos del señor como el ochavo de la viuda».

No es el mismo el caso de «La Religión», de Castelar [27-I: h. 1v. c. 2-3], quien apela a la fe verdadera para poder superar la magnitud de la tragedia que supuso el terremoto para más de un centenar de poblaciones andaluzas, porque «Dios queda en el fondo de los espacios y en el seno de las conciencias», porque la religión "durará $[. .$.$] tanto$ como el hombre dure, y allá en el cielo existirá eternamente con dios», lo que generará «una grande aspiración que sube a las alturas, y una grande inspiración que, desde las alturas, desciende sobre las almas». Y, aunque en este caso, el género híbrido del texto, de carácter persuasivo y opinativo, no es tan evidente como en los dos anteriores, los elementos que lo anclan a su pluridisciplinariedad son cuatro: su estructura -exordio, argumentación y peroración-; su lenguaje claro, correcto y sencillo -condición sine qua non de la re- 
dacción periodística, tanto en información, como en opinión-; la referida conexión con la actualidad; y una gran cantidad de figuras retóricas. Todos estos elementos lo convierten en lo que hoy llamaríamos una columna periodística, caracterizada, a menudo, aún hoy en día, por cabalgar entre Periodismo y Literatura, lo que se permite por ir firmado por una personalidad de un ámbito conocido por el lector.

Por su parte, Alarcón [27-I: h. 1v, c. 4-h. 2r. c. 1], también en torno a la imprescindible caridad -«inextinguible veneno de felicidad, paz y dulzura para los afligidos y los bienhechores»-, entiende que la fuerza moral que la caracteriza es superior a la fuerza física del terremoto y a la social, visualizada en casa de Fernán-Núñez.

Por último, la composición más compleja, y también llena de literariedad, sobre todo estructural, es la de Joaquín Costa [27-I: h. 2v. c. 2-3], «El breviario del Labrador», donde pormenoriza las calamidades naturales a las que el labrador tiene que hacer frente, para acabar con otras plagas no menos dañinas y que constituyen una crítica política y social feroz: el agente del fisco que recauda lo poco que le queda de la cosecha; el ejército, que se lleva lejos a sus hijos; el cacique opresor; y «las clases ilustradas, que no le tienden la mano». Finalmente, denuncia que, el labrador, «entre negativas, y maldiciones, y conjuros, camina tristemente desde la cuna al sepulcro, siendo su vida una maldición» y una lucha constante «contra la naturaleza, su enemiga, y contra la sociedad, su madrastra», lo que convierte este artículo en un ejemplo paradigmático del regeneracionismo de su creador.

Este año 2021, tan lleno de calamidades en España que llenan todos los días los medios de comunicación y las redes sociales, con una pandemia (COVID-19) en la que se han contagiado casi cinco millones de españoles y han fallecido casi noventa mil, la percepción de la actitud de los medios está muy lejos de la humilde prensa del XIX. La causa de esta aparente desafección puede estar en la cobertura 
oficial ante este tipo de acontecimientos, pero el caso es que nada tiene que ver con el entusiasmo de la prensa de hace cien años, aunque también comprometida con ideales políticos, materiales o personales, ya que siempre se mostró, sobre todo, al servicio de una sociedad muy frágil, a la que ella misma pertenecía.

Sorprende, de igual manera, el mismo y generoso compromiso de las personas, muchas ilustres y ya entonces con reconocimiento general en sus respectivos principales desempeños, que colaboraron generosamente con el número extraordinario de El Día, como lo hacían en otras muchas ocasiones; ocasiones en que la prensa española siempre encabezaba las iniciativas prontas, públicas y transparentes, dando cuenta de cada uno de los reales de los españoles que recibía.

\section{BIBLIOGRAFÍA}

ALARCón, Pedro Antonio (1891): «La fuerza física, la fuerza social y la fuerza moral», en Últimos escritos (Madrid, Imprenta y fundición de M. Tello), 143-150.

AXEITOS VALIÑO, Ricardo (2017): Las agencias periodísticas y literarias a fines del siglo XIX: las colaboraciones de Emilia Pardo Bazán y Clarín, Tesis doctoral Universidad de La Coruña, 24 de julio de 2017

https://ruc.udc.es/dspace/bitstream/handle/2183/19436/AxeitosValino _Ricardo_TD_2017.pdf [04-04-2021].

GARCía PinACHO, M. Pilar (2014): «La prensa en la formación de redes de poder (1863-1902)», en El Tiempo de Galdós (Las Palmas de Gran Canaria, Cabildo Insular de Las Palmas de Gran Canaria), 43-58.

García Pinacho, M. Pilar y Menéndez OnRubia, Carmen (2021): «"La Hija Mimada" (1885): un desconocido relato breve de Galdós", en Galdós. Cien años de actualidad, ed. M.A. Varela Olea (Berna (Suiza), Peter Lang), 67-88.

Gener, Pompeyo (1880): «La littérature au second centenaire de Don Pedro Calderón de la Barca», en Le Livre, revue mensuelle (París), 393-394. 
Lasala y Collado, Manuel (1888): Memoria del Comisario Regio, Madrid, Minuesa de los Ríos.

LISSORGUES, Yvan (2009): "Los suplementos literarios de "El Día” (18811886): una voluntad de regeneracionismo (o de regeneración) cultural», en Actas del Congreso Internacional celebrado en Lugo, 25-28 de noviembre de 2008, Literatura hispánica y prensa periódica (1875-1931), ed. J. Serrano Alonso y A. de Juan Bolufer (Santiago de Compostela, Universidad de Santiago de Compostela), 63-86.

López Arroyo, Alfonso; Martín Martín, Antonio Jesús; y Mezcua RodríGUEZ, Julio (1981): Los terremotos de Andalucía, Madrid, Presidencia de Gobierno-Instituto Geográfico Nacional.

KranZ, Janette (2020): El Periodismo Literario de Leopoldo Alas «Clarín», Madrid, Fundación Universitaria Española (FUE).

OSSORIO Y BERNARD, Manuel (1903): Ensayo de un catálogo de periodistas españoles del siglo XIX, Madrid, Imprenta y litografía de J. Palacios.

SAILlard, Simone (2005): “El (primer) Día” del marqués de Riscal», en Prensa, impresos, lectura en el mundo hispánico contemporáneo: homenaje a Jean-François Botrel, ed. J-M. Desvois (Burdeos, Université Michel de Montaigne Bordeaux 3), 347-362.

\section{REFERENCIAS HEMEROGRÁFICAS POR PERIÓDICOY FECHAS}

\section{El Balear (PALMA DE MALlORCA)}

OBRADOR, Ramón (1885): «Concierto-rifa de los señores duques de Fernán-Núñez», El Balear, 4-II, [1]-2.

T. J., (1885): «Correspondencia. Madrid 29 de enero», El Balear, 4-II, 2.

EL BIEN PÚBLICO (MAHÓN, MENORCA)

ANÓNimo (1885): «Telegramas. Servicio especial de El Bien Público», El Bien Público, 28-I, 3.

ANÓNIMO (1885): «Correo de hoy», El Bien Público, 29-I, 2.

Almaviva [Escobar y RAmíreZ, Alfredo] (1885): «Los duques de FernánNúñez. Madrid, 28», El Bien Público, 4-II, [1]-2. 
El CONSTITUCIONAL DinÁSTICO (ALICANTE)

ANÓNIMO (1885): «La Vida madrileña», El Constitucional Dinástico, 30-I, h. 1r. c. 3-5-h. 1v, c. 1.

EL CORREO DE CANTABRIA (SANTANDER)

ANÓNIMO (1885): «Noticias generales», El Correo de Cantabria, 30-I, h. 2r. c. 2.

LA CORRESPONDENCIA DE ESPAÑA (MADRID)

ANÓNIMO (1884): «Edición de la tarde de ayer 25 de diciembre», La Correspondencia de España, 26-XII, h. 1v. c. 4.

ANÓNIMO (1884): «Edición de la mañana de hoy 26 de diciembre», La Correspondencia de España, 26-XII, h. 2r. c. 4.

ANÓNIMO (1885): «Edición de la tarde de ayer 23 de enero», La Correspondencia de España, 23-I, h. 1v. c. 1.

ANÓNIMO (1885): «Edición de la tarde de ayer 25 de enero», La Correspondencia de España, 26-I, h. 1r. c. 4.

ANÓNIMO (1885): «Edición de la tarde de ayer 27 de enero», La Correspondencia de España, 28-I, h. 1v. c. 1.

ANÓNIMO (1885): «Edición de la noche de hoy 28 de enero», La Correspondencia de España, 29-I, h. 2r. c. 3.

CRÓNICA MERIDIONAL (ALMERÍA)

ANÓNimo (1885): «Sociedad de Socorros mutuos la Bienhechora», Crónica Meridional, 13-I, h. 1r. c. 1-4.

ANÓNIMO (1885): «En el Círculo de la Unión Mercantil», Crónica Meridional, 13-I, h. 2r. c. 1-2.

ANÓNIMO (1885): «Donativos, suscriciones y ofrecimientos», Crónica Meridional, 13-I, h. 2r. c. 2-4.

ANÓNimo (1885): «Gacetilla», Crónica Meridional, 13-I, h. 2r. c. 3-4.

EL DEMÓCRATA (GERONA)

A.L. (1885): "Correspondencia de El Demócrata. Cartas de Madrid. 28 de enero de 1885», El Demócrata, 1-II, 2.

EL DEMÓCRATA (MADRID) 
ANÓNIMO (1888): «Opiniones y comentarios», El Demócrata, 23-IV, h. 1v. c. 1.

EL DÍA (MADRID)

ANÓNIMo (1880): «El Día. Diario Político», El Día, 1-II, h. 2v. c. 1-4.

ANÓNIMO (1885): «Los terremotos», El Día, 3-I, h. 1v. c. 2.

AlarCón, Pedro Antonio de (1885): «La fuerza física, la fuerza social y la fuerza moral», El Día. Número extraordinario, 27-I, h. 1v, c. 4-h. 2r. c. 1.

ANÓNIMO (1885): «Lo que dice la fría razón», El Día. Número extraordinario, 27-I, h. 2v. c. 4.

Beruete, Aureliano de (1885): [«Una playa»], El Día. Número extraordinario, 27-I, h. 2r. 1-4.

CAMPOAMOR, Ramón de, (1885): «Los terremotos», El Día. Número extraordinario, 27-I, h. 1v. c. 3.

CANO, Leopoldo (1885): «El ochavo de la viuda», El Día. Número extraordinario, 27-I, h. 2v. c. 1.

CASTElaR, Emilio (1885): «La religión», El Día. Número extraordinario, 27-I, h. 1v. c. 2-3.

Conde de Casa Valencia [Alcalá-Galiano y Valencia, Emilio] (1885): «Caridad», El Día. Número extraordinario, 27-I, h. 2v. c. 1.

Conde de las almenas [Palacio y García de Velasco, Francisco Javier de] (1885): «La ley del fuerte», El Día. Número extraordinario, 27I, h. 2v. c. 1-2.

CosTA, Joaquín (1885): «El breviario del labrador», El Día. Número extraordinario, 27-I, h. 2v. c. 2-3.

DOCTOR HisPanUs [Vera y LÓPEZ, Vicente] (1885): «Los ruidos subterráneos en los terremotos», El Día. Número extraordinario, 27-I, h. 2v. c. 3-4.

ECHEGARAY, José (1885): «El terremoto y la caridad», El Día. Número extraordinario, 27-I, h. 2r. c. 1.

GOMAR, A. (1885): [«Un recuerdo de Granada»], El Día. Número extraordinario, 27-I, h. 2r. c. 2-3.

GuILlÉN BUZARÁN, Juan (1885): «El envidioso», El Día. Número extraordinario, 27-I, h. 2v. c. 3. 


\section{PILAR GARCÍA PINACHO}

GutiÉRreZ ABASCAL, José (1885): «El palacio de Cervellón y sus fiestas», El Día. Número extraordinario, 27-I, h. 1r-1v. c. 1-2.

Houghton, Carrie (1885): «El ochavo de la viuda», El Día. Número extraordinario, 27-I, h. 2r. c. 4-h. 2v. c. 1.

LENGO, Horacio (1885): «Viva Alfonso XII. Viva la caridad. Recuerdos de Málaga», El Día. Número extraordinario, 27-I, h. 2v. c. 2-3.

MÉlidA, Arturo (1885): [«La Caridad. Escudos de Granada y Málaga. Las armas de la casa de Cervellón»], El Día. Número extraordinario, 27-I, h. 1r. c. 2-3.

Moret y Prendergast, Segismundo (1885): «La caridad», El Día. Número extraordinario, 27-I, h. 1v. c. 3-4.

NúÑEZ DE ARCE, Gaspar (1885): «Oscuridad», El Día. Número extraordinario, 27-I, h. 1v. c. 4.

Ortiz de Pinedo, Manuel (1885): «Caridad!», El Día. Número extraordinario, 27-I, h. 2v. c. 1.

PARdo BAZÁN, Emilia (1885): «Conjetura», El Día. Número extraordinario, 27-I, h. 1v. c. 4.

PÉrez Galdós, Benito (1885): «La hija mimada», El Día. Número extraordinario, 27-I, h. 2r. c. 1-4.

Rodríguez CorreA, Ramón (1885): «Improvisación», El Día. Número extraordinario, 27-I, h. 2v. c. 4.

Rodríguez, Gabriel (1885): «Las fuerzas naturales», El Día. Número extraordinario, 27-I, h. 2v. c. 1.

Zorrilla, José (1885): «iA Granada!», El Día. Número extraordinario, 27-I, h. 1v. c. 2.

ANÓNimo (1885): «El número extraordinario de El Día», 28-I, h. 1r. c. 1.

ANÓNIMO (1885): «El concierto y la rifa de los duques de Fernán-Núñez», El Día, 28-I, h. 1r. c. 2-4.

DIARIO OFICIAL DE AVISOS DE MADRID

ANÓnimo (1880): «Noticias», Diario Oficial de Avisos de Madrid, 23-IV, 2.

LA DiNASTÍA (BARCELONA)

ANÓNimo (1885): La Dinastía, 4-I, 64-65. 
LA ÉPOCA (MADRID)

ANÓNIMO (1885): «Reunión de la prensa», La Época, 3-I, h. 2r. c. 3.

ANÓNIMO (1885): «Ecos madrileños», La Época, 23-I, h. 2r. c. 4.

EL FÍGARO (MADRID)

ANÓNIMO (1880): «Noticias», El Fígaro, 23-I: h.1v.c. 1.

GACETA DE MADRID (MADRID)

GARRIDO ESTRADA, Eduardo (1880): «Nota de la recaudación obtenida por el derecho del timbre de periódicos para la Península, Antillas y Filipinas», Gaceta de Madrid, 17-VIII, 515-516.

(1880): «Nota de la recaudación obtenida por el derecho de timbre de periódicos para la Península, Antillas y Filipinas», Gaceta de Madrid, 16-IX, 889.

GARCÍA DE TORRES, Juan (1882): «Nota de la recaudación obtenida por derecho del timbre de periódicos para la Península, Antillas y Filipinas, con expresión del número de ejemplares de cada uno de los periódicos cuya tirada está intervenida por la Hacienda», Gaceta de Madrid, 15-I, 224.

(1883): «Nota de la recaudación obtenida por derecho del timbre de periódicos para la Península, Antillas y Filipinas, con expresión del número de ejemplares de cada uno de los periódicos cuya tirada está intervenida por la Hacienda», Gaceta de Madrid, 17-I, 129-130.

EL GLOBO (MADRID)

ANÓNIMO (1884): «Temblor de tierra», El Globo, 26-XII, h. 1v. c. 1.

ANÓNIMO (1884): «Los temblores de tierra en Andalucía», El Globo, 30-XII, h. 2 r. c. 1.

EL GUADALETE (JEREZ DE LA Frontera, CÁdiZ)

Almaviva [Escobar y RAmírez, Alfredo] (1885): «En casa de FernánNúñez», El Guadalete, 30-I, h. 1r. c. 5-h. 1v. c. 1.

LA IBERIA (MADRID)

ANÓNIMO (1885): «Buen ejemplo», La Iberia, 3-I, h. 2r. c. 2-3. 


\section{PILAR GARCÍA PINACHO}

EL IMPARCIAL (MADRID)

ANÓNIMO (1884): «Los temblores de tierra. En Madrid», El Imparcial, 26XII, h. 1v. c. 3.

ANÓNIMO (1884): «Los temblores de tierra. En provincias», El Imparcial, 26-XII, h. 1v. c. 3.

ANÓNimo (1885): «La caridad española», El Imparcial, 3-I, h. 1r. c. 1-2.

Almaviva [Escobar y RAMíREZ, Alfredo], (1885): «La vida madrileña», El Imparcial, 28-I, h. 2r. c. 2-4.

EL LIBERAL (MADRID)

ANÓNIMO (1880): «A vuela pluma», El Liberal, 23-I, h.1r. c. 4

ANÓNIMO (1884): «El terremoto de anoche», El Liberal, 26-XII, h. 1r-v. c. 2.

ANÓNIMO (1884): «iCaridad!», El Liberal, 31-XII, h. 1r. c. 1.

ANÓNIMO (1885): «Buen ejemplo», El Liberal, 3-I, h. 2r. c. 2.

ANÓNIMO (1885): «Cartera de Madrid» El Liberal, 3-I, h. 2r. c. 3.

ANÓNIMO (1885): «Donativos, suscriciones y ofrecimientos», El Liberal, 25I, h. 2r. c. 1.

ANÓNimo (1885): «Cartera de Madrid», El Liberal, 27-I, h. 2r. c. 2-3.

EL LITORAL (GANDÍA, VALENCIA)

ANÓNIMO (1885): «Revista General», El Litoral, 1-II, h. 1r. c. 1.

\section{LA LUCHA (GERONA)}

El Corresponsal (1885): «Madrid 29 de enero de 1885», La Lucha, 1-II, h. 1 v. c. $3-4$.

NUEVO MUNDO (MADRID)

ANÓNimo (1907): «Gutiérrez Abascal. (Kasabal)», Nuevo Mundo 4-IV, h. 6v.

LA PAZ (MURCIA)

ANÓNIMO (1885): «Noticias generales», La Paz, 27-I, h. 1v. c. 4.

ANÓNIMO (1885): «Terremotos y socorros», La Paz, 29-I, h. 1v. c. 1-3.

ANÓNIMO (1885): «Terremotos y socorros», La Paz, 30-I, h. 1v. c. 1-2.

LA REPÚBLICA (MADRID) 


\section{LOS TERREMOTOS DE ANDALUCÍA (1884-1885)}

ANÓNIMO (1885): «La suscrición nacional», La República, 6-I, h. 1r. c. 4-h. 1v. c. 1 .

EL SERPIS (AlCOY, AliCANTE)

ANÓNIMO (1885): «Alcance. Madrid 28 enero 1885», El Serpis, 30-I, h. 2r. c. 2. 


\section{APÉNDICE}

\section{«LA RELIGIÓN». EMILIO CASTELAR}

No vacilemos en afirmarlo. Como hemos nacido sociales, como hemos nacido inteligentes, como hemos nacido libres, como hemos nacido hombres, hemos nacido sin remisión, por una ley natural o por una ley divina, religiosos y creyentes. Creemos como amamos. Vivimos en el espíritu como vivimos en el aire. Las ideas interiores del alma responden a las estrellas del espacio en su luz y en su infinidad. Por muchos dioses que se hayan derribado, por muchos templos que se hayan demolido, siquier los titanes del espíritu hayan puesto argumento sobre argumento para llevar al cielo etéreo y azul todas las anarquías de sus ideas personales, Dios queda en el fondo de los espacios y en el seno de las conciencias. A medida que nos levantamos a los aires, vemos negro lo que antes veíamos celeste; y el silencio y la soledad terminan en aquellas almas y en sus abismos cerúleos, como si los dominara el frío de la muerte; y sin embargo, de allí baja el calor que mueve la lengua de las aves y las cuerdas de las arpas, que pinta el cáliz de las flores y las alas de las mariposas, que enciende la boreal aurora en los horizontes enrojecidos y la chispa eléctrica en los nervios agitados, que pone su carmín puro en la sangre y su dulzor misterioso en las mieles; porque de allí viene la luz, alma del universo. No importa que unas veces tales ideas suban por Oriente, mientras otras ideas se avecinan al Ocaso; que tales templos aparezcan desiertos, mientras se llenan otros templos; que ascienda un cenobita y se ponga de hinojos sobre las aras de donde ha descendido sin tirso y sin corona la pitonisa de Delfos; que una rotonda, como la rotonda de Miguel Ángel, se levante cerca de una 
colina como la colina del Capitolio: la materia orgánica, en sus espirales y en sus parábolas, va buscando la perfecta organización del hombre, y la esencia y la sustancia espiritual buscan con sus ideales, y no solamente lo buscan sino que lo encuentran y lo conocen, al Eterno ser, al Dios Criador de las ideas y de las cosas. Ved cómo se une todo aquello que tiene alas, aromas, armonías, música en el Universo, con todo aquello que tiene intuiciones, fe, plegarias en las almas.

Envía el sereno lago vapores a las alturas; la flor se abre, y exhala esencias y guarda bálsamos; canta sus serenatas de amor, en fecundo abril sobre los nidos, enamorada el ave; los árboles de las selvas corónanse de guirnaldas que simbolizan y expresan misteriosos desposorios; las aladas luciérnagas, tan brillantes como los aerolitos, llenan de luminarias la inmensidad del horizonte por las noches tropicales; allá lejos, los astros centellean como lámparas encendidas en los atrios eternales de la infinita iglesia del espíritu; y más allá, mucho más lejos del éter, del magnetismo, de la electricidad, de la luz, de todo cuanto parece casi una idea en el universo mundo, el arte suena las cuerdas de las arpas, tiñe con bis las tablas y los lienzos, levanta las estatuas coronadas con diademas de inspiraciones, erige los templos cuyas altas ventanas miran hacia el Eterno, y cuyos bajos sepulcros sacan de los cadáveres descompuestos las almas inmortales para engarzarlas en los cielos místicos de la bienaventuranza. La realidad es una cristalización de la espiritualidad. Sobre las leyes naturales dominan las leyes ideales. Aquellas cuentan con la materia y con la fuerza, mientras cuentan estas con la libertad y con las ideas. Ningún átomo se aniquila en el mundo material, y ningún pensamiento se aniquila en el mundo espiritual. Mientras el dolor taladre nuestros corazones, y la duda, corone nuestras sienes con sus abrojos; mientras pueda venir la muerte a robarnos los seres queridos, y puedan las almas sumergirse a una en los misterios de la eternidad sin que responda a nuestros llamamientos y a nuestros reclamos, los planetas serán para todos aquellos que los habitan y los pueblan como naves que se perderían sin remedio, encallando su quilla en el fango, si no hinchase sus velas 
el viento de los cielos, y no tuviesen como polo fijo en la inmensa variedad de las cosas al eterno Dios. Existe una religión, como existe un Arte, como existe una Ciencia, como existe un Estado. Y para despojar a la humanidad entera del Estado, tendríais que hacerla completamente antisocial; y para despojarla del arte y sus ensueños, tendríais que arrancarle con el corazón todos los sentimientos; y para desalojarla de la Ciencia, tendríais que apagarle y extinguirle allá, en las facultades del alma, su razón y sus ideas; y para despojarla del templo, del altar, del claustro, del exvoto, tendríais que hacerla un ser inmoral o irreligioso. La religión durará aquí en la tierra tanto como el hombre dure, y allá en el cielo coexistirá eternamente con Dios, resultando una grande aspiración que sube a las alturas, y una grande inspiración que, desde las alturas, desciende sobre las almas.

\section{«CONJETURA». EMILIA PARDO BAZÁN}

Hoy que tantas se hacen acerca del origen de los terremotos, ¿por qué razón no he de emitir la mía?.

Yo creo que el globo, dócil caballo a cuyos lomos viaja por el espacio la humanidad, tiene a veces, como Rocinante, sus lozanías, y cansado del paso de andadura, se sacude y pega un bote o una huida de costado, destrozando algunos miles de edificios.

Suele ocurrírseme también que, indignado de llevar encima nuestra vil raza, se estremece y brinca, tratando de ser deseoso de librarse del humillante peso.

Mas si esto fuese verdad, no me parece probable que la inteligente montura empezase por desembarazarse de las modestas casas, de las pobres iglesias, de la buena gente campesina.

iNo, no! El globo obedece en sus convulsiones a una fuerza superior, oculta y fatal; de otro modo no desplomaría escombros sobre las cunas ni ahogaría bajo un techo a la madre con el niño en brazos. 


\section{«LA CARIDAD». SEGISMUNDO MORET}

Ninguno de los peligros que amenazan la existencia humana excede en espanto al que producen los temblores de la tierra. Cuando el cielo abre sus cataratas y lanza sus furores sobre el hombre, aun cuando lleguen a destruirse las casas y desplomarse las moradas, todavía contra las iras del firmamento le ofrecen asilo las grutas y las cavernas escondidas bajo la mole de las montañas. Cuando la inundación arrebata en rugiente carrera los pueblos y sus moradores, todavía el desgraciado náufrago entrevé, en su terrible lucha con la muerte, la rama de un árbol, y la acongojada madre, muda de terror, adivina el valiente brazo que detendrá la flotante cuna, donde va el hijo de sus entrañas. Cuando el enfurecido océano deshace sin piedad la nave, todavía el marino piensa en la insumergible tabla. Pero cuando el suelo se estremece, se abre la tierra, la morada se desploma y la gigantesca peña rueda sobre el valle, entonces, ante el espectáculo de la muerte en todos sus horrores, desaparecen a un tiempo todas las esperanzas. Solo una, que no muere jamás, brilla a lo lejos, y en medio de los horrores de la destrucción, se adelanta, como ángel de redención para el desamparado y de consuelo para el afligido: la Caridad.

\section{«EL OCHAVO DE LA VIUDA». CARRIE HOUGHTON}

Sucedió esto hace ya muchos años, cuando aún habitaba entre nosotros Nuestro Señor Jesucristo.

Allá en la Tierra Santa había ocurrido una desgracia inmensa, semejante a la que ahora contrita y aflige a dos extensas provincias de la hermosa Andalucía. En una de las plazas de Jerusalén había aparecido una enorme caja de piedra con una enorme abertura en la tapa y ostentando, esculpida en gruesos caracteres, la palabra Caridad. Día y noche acudieron los hijos de la Ciudad Santa a depositar en ella lo 
que podían ofrecer a sus atribulados hermanos. Allí fue el rico fariseo, ataviado con el manto de fino hilo y el morado turbante, y al poner la mano sobre la caja, oyóse en su fondo el agudo sonido que produce el oro al herir la piedra. Allí fue la judía, cubierta con blanquísimo velo, los brazos con áureos brazaletes y sujeta la hermosa cabellera por numerosos hilos de gruesas perlas, y escuchose en la caja el mismo sonido. Allí fue el mercader guiando su asno, cargado de ricas telas, y depositaba el fruto de su constante trabajo y largos viajes. Así fueron desfilando por delante de la caja ricos y pobres; y hasta la humilde sierva, al volver de la fuente, con el cántaro de agua en la cabeza, tuvo una moneda para aumentar el fondo de socorro.

Era muy entrada la noche, y la plaza estaba casi desierta, cuando una mujer enlutada y muy pobremente vestida, que llevaba de la mano a un niño, se acercó y sacando del bolsillo un ochavo, lo echó, llorando, en la caja de piedra. Al retirarse oyó una voz que la interrogaba:

- Mujer, ¿̇cuál ha sido tu limosna?

Abrió los ojos, y vio la divina figura de Profeta, nombre que en Jerusalén daban al Hijo de Dios.

-Yo, señor, he dado cuánto tenía, un ochavo- replicó avergonzada y algo temerosa de que el Señor la reprendiera por su mezquindad. Pero Jesucristo, con voz clara le dijo:

-Mujer, un ochavo vale más a los ojos de mi padre que el oro del fariseo, porque él tiene mucho y tú nada. La limosna de una viuda es limosna bendita y iay de aquel que robe a las viudas y huérfanos!

Tales fueron las palabras del Señor.

Al contemplar ahora el triste cuadro que ofrecen las ruinas de las que no mucho eran ricas poblaciones como Alhama y Albuñuelas, a nadie le es dado decir: No tengo más que para mí, ni nadie debe obediencia al impulso de un mal disfrazado orgullo, retener su limosna por lo mezquina; que estos pequeños óbolos sumarán millones para remediar muchos males y serán tan gratos a los ojos del Señor como el ochavo de la viuda. 


\section{«EL BREVIARIO DEL LABRADOR». JOAQUÍN COSTA}

Como en el rito eclesiástico hay una oración para cada día del año y para cada hora del día, el calendario del labrador tiene para cada estación, para cada luna, para cada minuto, un ser que maldecir. Maldice un día a la nube, que pasa sin humedecer sus calcinados surcos, y al siguiente, porque ha llovido demasiado, robándole la capa vegetal que había creado con su sudor y constituía toda su riqueza; maldice un día al sol porque luce con demasiado brillo y le abrasa las plantas, y al siguiente, porque queda velado tras de nubes, y la atmósfera no se calienta, y sus cosechas sufren peligrosos retrasos; maldice a la nieve cuando cae, porque hiela sus olivos, y cuando no cae, porque no se empapan las mieses ni se llena el pantano; maldice al rayo, que reduce a pavesas sus heniles; y al terremoto, que sepulta sus bestias bajo las ruinas de su cortijo y al huracán, que troncha sus árboles y apedrea sus viñas; y al torrente, que se hincha y arrasa sus acequias; y a la raposa, que diezma su gallinero; y a la hormiga, esa señora feudal, que le cobra pingüe tributo en el campo, en la era y en el granero; y a la langosta, que le siega, con sus mandíbulas de hierro, las espigas; y a la filoxera, que hipertrofia las raíces de la vid; y al pulgón, que chupa los jugos de las legumbres, matándolas de hambre; y a la cuscuta, que ahoga con sus abrazos de muerte la alfalfa y el trébol de los prados; y al micoderma, que torna en vinagre el vino reparador de sus lagares; y al hongo parásito, que extravasa la savia de sus frutales; y a los espinos, que se levantan a la altura de las ovejas, para arrancarles de sus vellones valijas de lana; y a la zarza y al matorral, que se asoman a la orilla del camino, extendiendo sus garras de infinitas uñas para robarle parte de la mies; y al agente del fisco, que le recoge las escasas sobras de la era; y al ejército, que le priva del auxilio de sus hijos; y al cacique que le oprime; y a las clases ilustradas, que no le tienden la mano, mientras él pesca su miseria por Europa a raíz de inundaciones y diluvios apocalípticos; y así, entre negativas, y 
maldiciones, y conjuros, camina tristemente desde la cuna al sepulcro, siendo su vida una maldición coreada contra la Naturaleza, su enemiga, y contra la Sociedad, su madrastra.

\section{«A GRANADA». JOSÉ ZORRILLA}

iGranada, ciudad bendita, / reclinada sobre flores, / si al vaivén de tus temblores, / en escombros te he de ver, / a mí y al rey drazarita, / que te hemos idolatrado, / mejor nos hubiera estado / ser ahogados al nacer!

Viejo y pobre, ya no vivo / para el mundo, ya no canto: / solo puedo inútil llanto / derramar ya sobre ti; / miserable lenitivo / de mis ansias postrimeras / fuera, si caes, que cayeras / ioh Granada!, sobre mí.

\section{«LOS TERREMOTOS». RAMÓN DE CAMPOAMOR}

I. -¿Qué haremos, cuando el cielo / casas y templos con fragor derriba? / -¿Qué haremos- preguntáis almas de hielo? / iTener fe en la justicia de allá arriba!

II. Conmueve de placer nuestras entrañas / el ver que, consolando ajenos males, / va la piedad, desde casas reales, / a barrer la miseria a las cabañas.

III. Cuando se abre la tierra estremecida, / el bueno reza, se resigna y muere, / que es el único sabio en esta vida / el que sabe querer lo que Dios quiere.

\section{«OSCURIDAD». GASPAR NÚÑEZ DE ARCE}

iSiempre el terrible enigma que nuestra mente acosa! / El mundo es un abismo tan hondo como el mar, / y el tiempo, ola invisible, rugiente y borrascosa, / empuja nuestra nave, sin rumbo y al azar. 
La humanidad avanza desorientada y ciega; / En torno suyo es todo misterio y lobreguez; / ¿Sabéis lo que el instante que apresurado llega / guarda en su seno? Alguna catástrofe tal vez.

\section{«EL TERREMOTO Y LA CARIDAD». JOSÉ DE ECHEGARAY}

Se engendra el terremoto en las montañas, / pero camina siempre a ras de suelo: / brota la caridad en las entrañas / del ser humano... y se remonta al cielo. 
ILUSTRACIONES

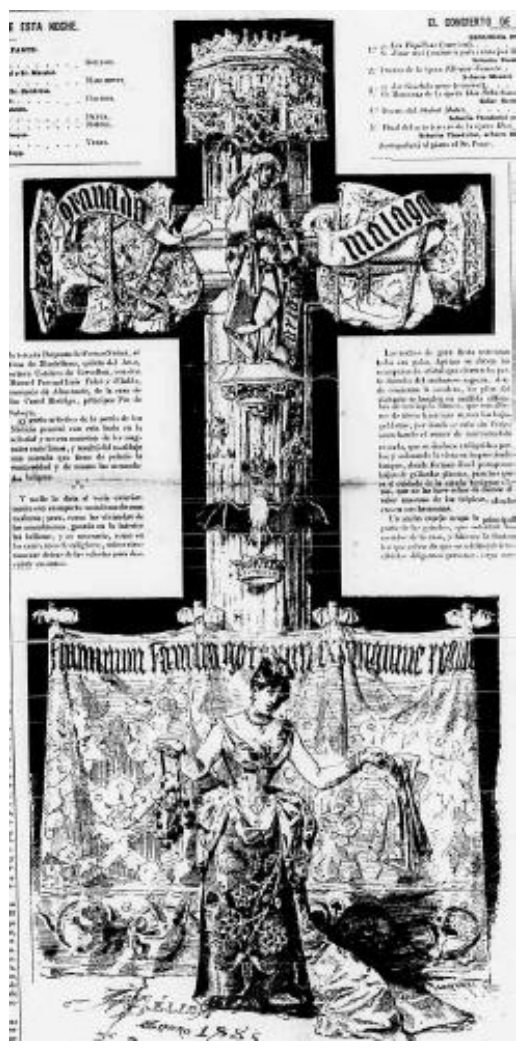

Imagen 1: MÉLIDA, Arturo (1885): [«La Caridad. Escudos de Granada y Málaga. Las armas de la casa de Cervellón»], El Día. Número extraordinario, 27-I, h. 1r. c. 2-3. 


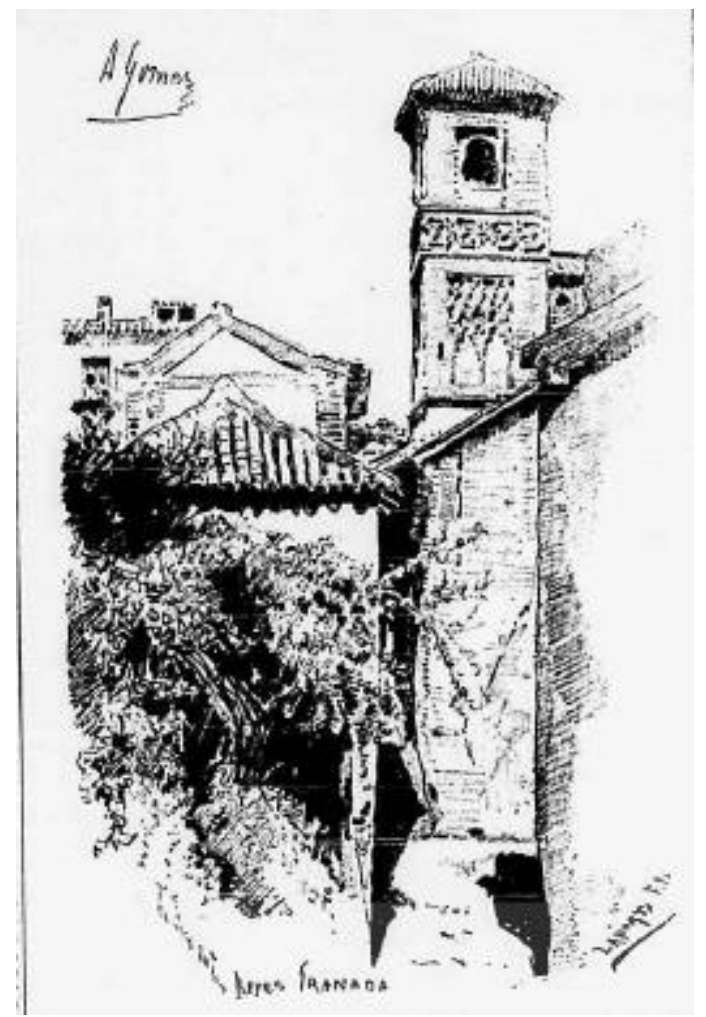

Imagen 2: GOMAR, A. (1885): [«Un recuerdo de Granada»], El Día. Número extraordinario, 27-I, h. 2r. c. 2-3. 


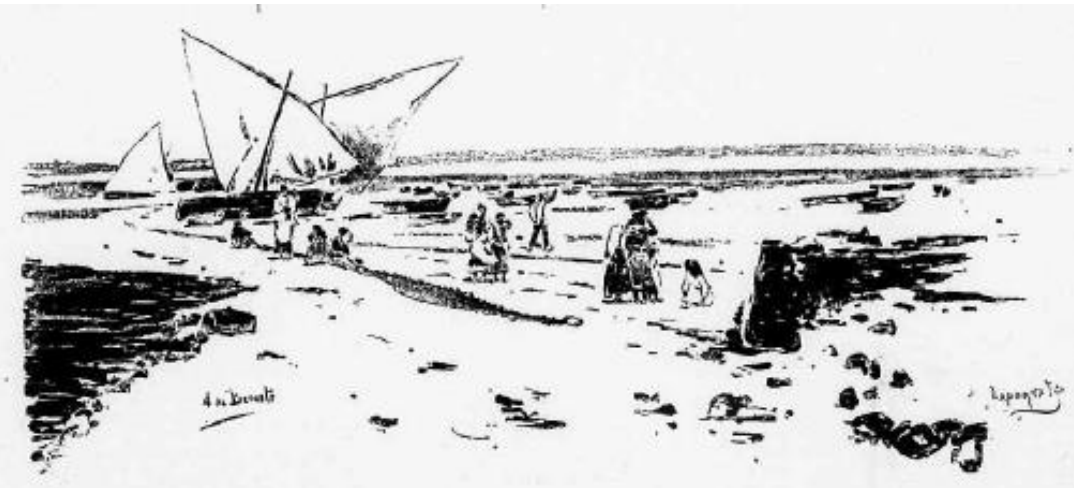

Imagen 3: BERUETE, Aureliano de (1885): [«Una playa»], El Día. Número extraordinario, 27-I, h. 2r. 1-4. 


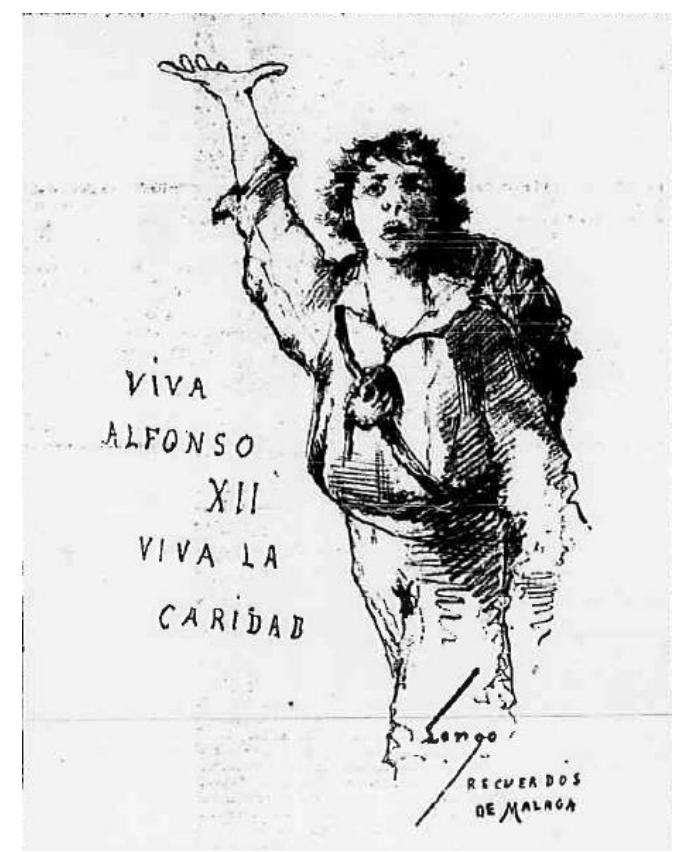

Imagen 4: LENGO, Horacio (1885): «Viva Alfonso XII. Viva la caridad. Recuerdos de Málaga», El Día. Número extraordinario, 27-I, h. 2v. c. 2-3. 